\title{
Producción y calidad de forraje con enmiendas orgánicas en pastura (Brachiaria Brizantha), en la Costa Caribe Sur de Nicaragua
}

\author{
Franklin Ariel López García' \\ Jarling Alberto Miranda ${ }^{2}$ \\ Wilson Antonio Calero Borge ${ }^{3}$
}

\section{Resumen}

$\mathrm{F}_{\mathrm{n}}$ esta investigación se ha aplicado diferentes alternativas orgánicas para determinar sus efectos en Ela producción y calidad de forraje en Brachiaria brizantha. En el estudio se evaluaron tres tipos de enmiendas orgánicas (Lombrihumus, Bokashi y EM) en el pasto Brachiaria brizantha, las que fueron comparados con un tratamiento testigo (sin enmienda orgánica). Se empleó un diseño de bloque completamente al azar (BCA), 4 réplicas por tratamiento para un total de 16 parcelas, evaluado en pasturas ya establecidas. La mayor producción de biomasa verde es de $17,325 \mathrm{~kg} / \mathrm{h}$ a al aplicar lombrihumus, en producción de materia seca el lombrihumus obtuvo el mayor rendimiento (3,383 kg/ha). La mayor longitud de raíces primarias se obtuvo al aplicar lombrihumus $(17.25 \mathrm{~cm})$. En la variable relación hoja/tallo los mayores resultados se obtuvieron con Lombrihumus. Con bokashi se obtuvieron los mayores porcentajes de digestibilidad de la materia seca $(62 \%)$, proteína bruta $(9.8 \%)$ y cenizas (9.52\%). El lombrihumus y bokashi ejercieron los mayores efectos en las variables evaluadas en Brachiaria brizantha. Se recomienda el uso de alternativas orgánicas para optimizar la producción y calidad de la pastura Brachiaria brizantha.

Palabras clave: producción, calidad, forraje, enmienda orgánica, pastura.

\section{Abstract}

In this research, different organic alternatives have been applied to determine their effects on forage's production and quality in Brachiaria brizantha. The study evaluated three types of organic amendments (Lombrizhumus, Bokashi and EM) in the Brachiaria brizantha grass, which were compared with a witness treatment (no organic amendment). A completely randomized block design (BCA) was used, 4 replicates per treatment for a total of 16 plots, evaluated in established pastures. The highest production of green biomass is $17.325 \mathrm{~kg} / \mathrm{ha}$ when applying lombrihumus; in dry matter production lombrihumus obtained the highest yield $(3.383 \mathrm{~kg} / \mathrm{ha})$. The largest length of primary roots was obtained by applying lombrihumus $(17.25 \mathrm{~cm})$. In the leaf/stem ratio variable the greatest results were obtained with Lombrihumus; With Bokashi were obtained the highest percentage of dry matter digestibility (62\%), crude protein (9.8\%) and ash (9.52\%). Lombrihumus and bokashi had the greatest effects on the variables evaluated in Brachiaria brizantha. The use of organic alternatives is recommended to optimize the production and quality of the Brachiaria brizantha pasture.

Keywords: Production, quality, forage, organic amendment, pasture.

\footnotetext{
1 Ingeniero en Zootecnia. Correo: lopezfranklin89@yahoo.com

2 Ingeniero en Zootecnia. Correo: investigacion.ng@uraccan.edu.ni

3 Máster en Agroforestería Tropical. Coordinador Investigación de la Universidad de las Regiones Autónomas de la Costa Caribe Nicaragüense-Recinto Universitario Nueva Guinea. Correo: investigacion.ng@uraccan.edu.ni
}

Recibido: 05/06/2017 Aprobado: 22/06/2017 


\section{Introducción}

La ganadería bovina es una de las actividades productivas de mayor importancia en la economía nicaragüense (Castro, 2010), el Municipio de Nueva Guinea es de vocación forestal y agroforestal, pero ha sido transformada en zona ganadera. Los suelos del municipio, dedicados a pasturas son de fertilidad media a baja y acidez alta, esto incide en calidad y producción de pasturas (Prado, 2004). La fuente principal de alimentación ganadera son las gramíneas y leguminosas, sin embargo, la baja disponibilidad de pastos ricos en nutrientes, inciden en la producción y calidad de leche (Delgadillo, 2009).

El uso de enmiendas orgánicas en pasturas, asegura mejores resultados en el desarrollo de estos. Su uso garantiza alimentación rica en nutrientes, mejor producción y reproducción, por otro lado, mejora la fertilidad de los suelos incorporándoles macro y micro organismos que permitan la retención e infiltración de agua y sales minerales (Delgadillo, 2009). Se pretende que los productores adopten nuevas formas de producir, una forma de lograrlo es haciendo uso de enmiendas orgánicas (IPADE -PRODESOC, 2009).

\section{Revisión de literatura}

Pasto es el nombre general que reciben diversas hierbas, es el alimento vegetal que crece en el suelo y se destina a la alimentación animal. Los pastos constituyen la fuente de alimentación más económica de que dispone un productor para mantener los animales. Sin embargo, depende de un manejo adecuado el que un pasto desarrolle todas las funciones de crecimiento, producción y reproducción en los animales (Ganaderos, 2008).

Los pastos tienen crecimiento erecto y rastrero, los primeros crecen en forma perpendicular al suelo, en pastoreo son los de menor rendimiento en cuanto a cantidad de forraje, son más susceptibles a la aparición y crecimiento de muchas plantas arvenses, los segundos crecen paralelos al suelo, son de muy buena cobertura vegetal y más resistente al pisoteo, compiten naturalmente con otras plantas (BUILES, 2008), también hay pastos de crecimiento semi-erecto en estos el tallo no es totalmente erecto o rastrero.

El pasto Brizantha es originario de África Oriental, su nombre común es Marandù o Brizantha. El clima favorable es cálido, altura en- tre o y 1000 m.s.n.m, los suelos deben ser fértiles con buen drenaje y altos contenidos de materia orgánica, su densidad de siembra es de $4-6 \mathrm{~kg} / \mathrm{ha}$ (semilla pura), su ciclo vegetativo es denominado perenne, su palatabilidad es de muy buena y toxicidad no posee (Carrero, 2012). El valor nutritivo se considera entre moderado y bueno, si se compara con otras especies de Brachiaria, en relación con su palatabilidad, consumo, digestibilidad y composición química (FAO, 2012).

Los abonos orgánicos son todos los materiales de origen orgánico que se pueden descomponer por la acción de microorganismos y del trabajo del ser humano y ayudan al suelo a mantener su fertilidad (Gurierrez, 2009).

\section{Métodos y materiales}

Esta investigación es de carácter cuantitativa, se realizó en la finca Regalo de Dios colonia Yolaina, Municipio de Nueva Guinea, Región Autónoma Costa Caribe Sur de Nicaragua. Para ello, se utilizó un Bloque Completamente al Azar (BCA), se establecieron 4 réplicas por tratamiento para un total de 16 parcelas experimentales, el ensayo se estableció en pasturas ya establecidas. Los tratamientos son:

- Tratamiento 1 (T1): Se aplicó el abono orgánico Lombrihumus a las pasturas, a base de $2272.72 \mathrm{~kg} / \mathrm{ha}$.

- Tratamiento 2 (T2): se aplicó abono orgánico Bokashi, a razón de $2045.45 \mathrm{~kg} / \mathrm{ha}$ (Prado, 2004).

- Tratamiento 3 (T3): se aplicó EM a las pasturas, la dosis fue 60 litros/ha.

- Tratamiento $4\left(\mathrm{~T}_{4}\right)$ : Este tratamiento correspondió al testigo, no se le aplicó ninguna enmienda orgánica.

Manejo del ensayo. Las mediciones de las parcelas se realizaron con una frecuencia mensual. El suelo donde se estableció el ensayo corresponde al tipo ultisol (Calero, 2013). Las variables medidas han sido: producción de biomasa verde; producción de materia seca; calidad de las pasturas: Mediante examen bromatológico en laboratorio de Universidad Nacional Agraria (UNA); cobertura; longitud de raíces primarias; longitud de raíces secundarias; relación hoja/tallo. El procesamiento y análisis de la información consistió en análisis descriptivo e inferencial de los datos mediante el programa infostat, ANDEVA y prueba de Duncan. 


\section{Resultados y discusión}

\section{Efecto de los abonos orgánicos en la producción de biomasa de la pastura Brachiaria brizantha}

\section{Producción de materia verde}

El análisis de varianza (ANDEVA) figura 1, refleja que en el tercer corte hay efecto significativo de los tratamientos, los mayores valores se obtienen cuando se aplica Lombrihumus (17,325 kg/ha) y Bokashi $(14,825 \mathrm{~kg} / \mathrm{ha})$.

El primer corte no muestra diferencia en rendimiento de materia verde, esto se debe a que el periodo de aplicación de los tratamientos, aun no es suficiente para que se pueda manifestar el efecto del tratamiento en la producción de materia verde, Campos (2010) afirma que la mayoría de los abonos orgánicos son de acción lenta, pues proporcionan Nitrógeno orgánico que debe ser transformado en inorgánico por las bacterias del suelo antes de ser absorbidas por las raíces. Estudios realizados por Miranda (2009) afirman que el cultivar Brachiaria brizantha produce 12,133 Kg/ha de forraje fresco. Por otra parte, Aguilar (1997) obtuvo con diferentes frecuencias de corte entre 8967 y $8123 \mathrm{~kg} / \mathrm{ha}$; en este estudio fue mayor la producción de materia verde en comparación con resultados obtenidos de otras investigaciones.

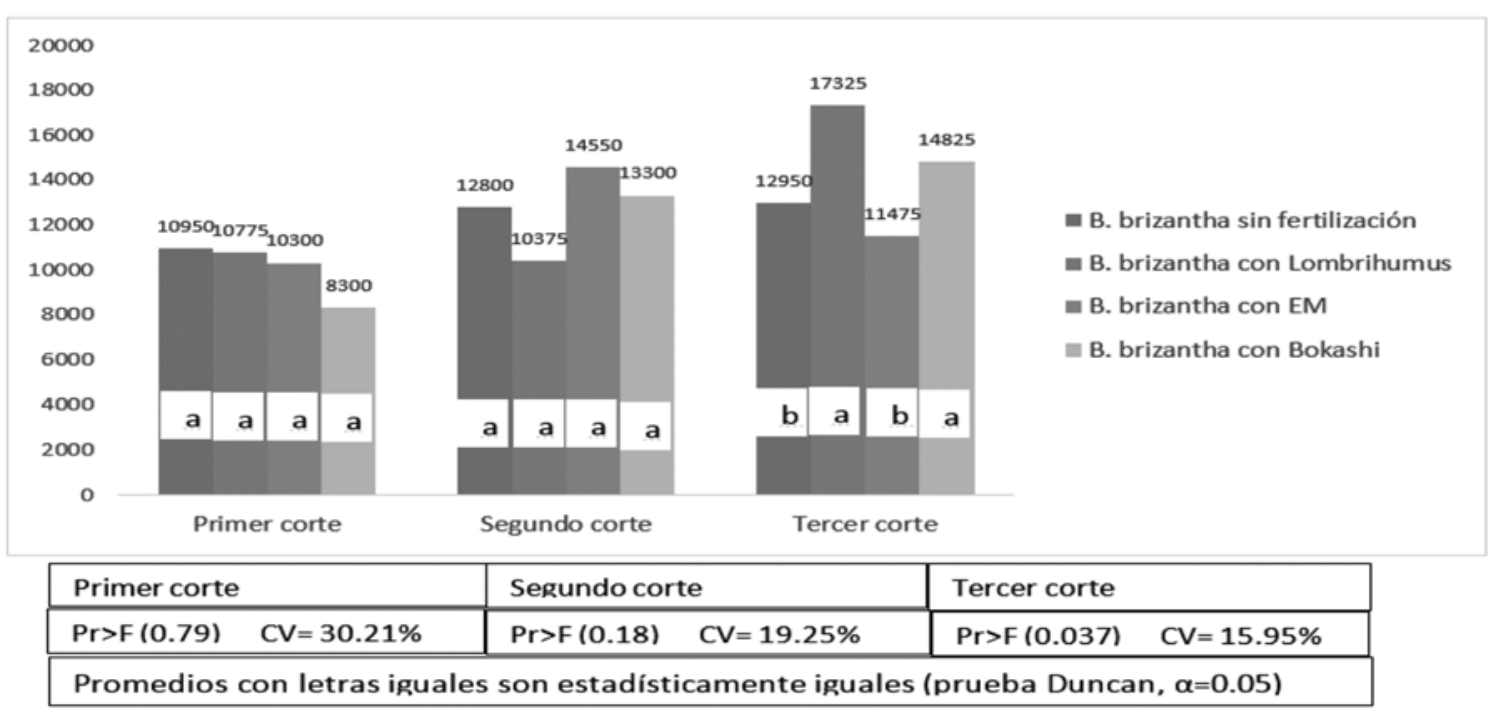

Figura 1: Producción de materia verde (Kg/ha) de Brachiaria brizantha bajo diferentes alternativas de fertilización.

\section{Producción de materia seca}

En la figura 2 para la producción de materia seca refleja que durante los tres cortes del pasto hay efecto significativo, en el tercer corte los tratamientos con Lombrihumus y Bokashi tienen los mayores rendimientos, esto debido a que su incorporación al sistema radicular y vascular es más lenta, considerando el grado de mineralización de los elementos nutritivos que contienen los abonos orgánicos. Los datos obtenidos tienen similitud con Aguilar (1997) quien con frecuencia de corte de 27 días obtuvo $2383.1 \mathrm{~kg} /$ ha, superan los reportados por Roig (2010) quien indica rendimientos de 8 a 10 t/ha por año. De acuerdo a Prado (2004) con fertilización orgánica obtuvo $2490.90 \mathrm{~kg} / \mathrm{ha} /$ corte, siendo inferiores a los del actual estudio. 


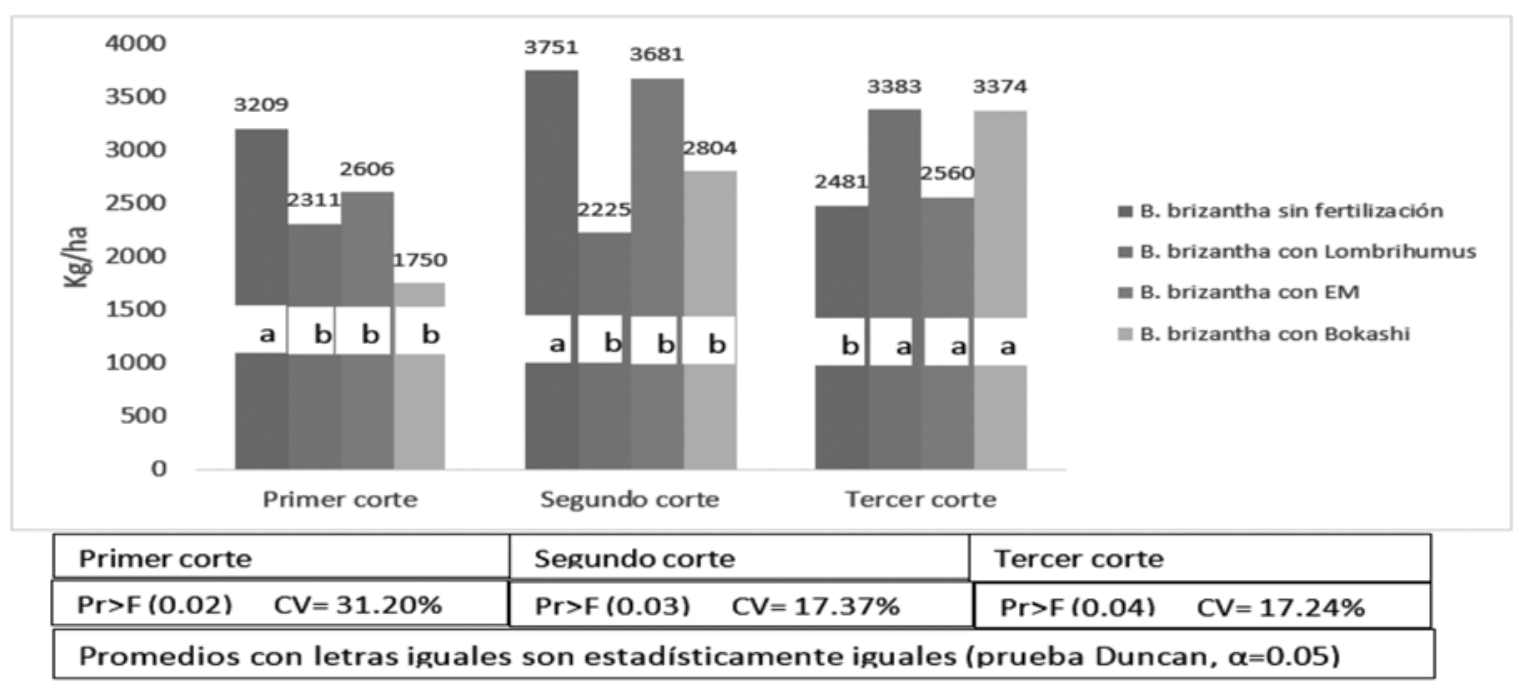

Figura 2: Producción de materia seca (Kg/ha) de Brachiaria brizantha bajo diferentes alternativas de fertilización.

\section{Cobertura}

El ANDEVA (figura 3), muestra que a medida que el pasto se establecía plenamente los mayores resultados se expresaron en los tratamientos con lombrihumus, Bokashi y EM; aumentando su porcentaje de cobertura. Estudios realizados por Campos (2010) plantea que la aplicación de abonos orgánicos mejora la cobertura basal y aérea, por cuanto la cobertura basal de las plantas del grupo del testigo presenta un porcentaje inferior.

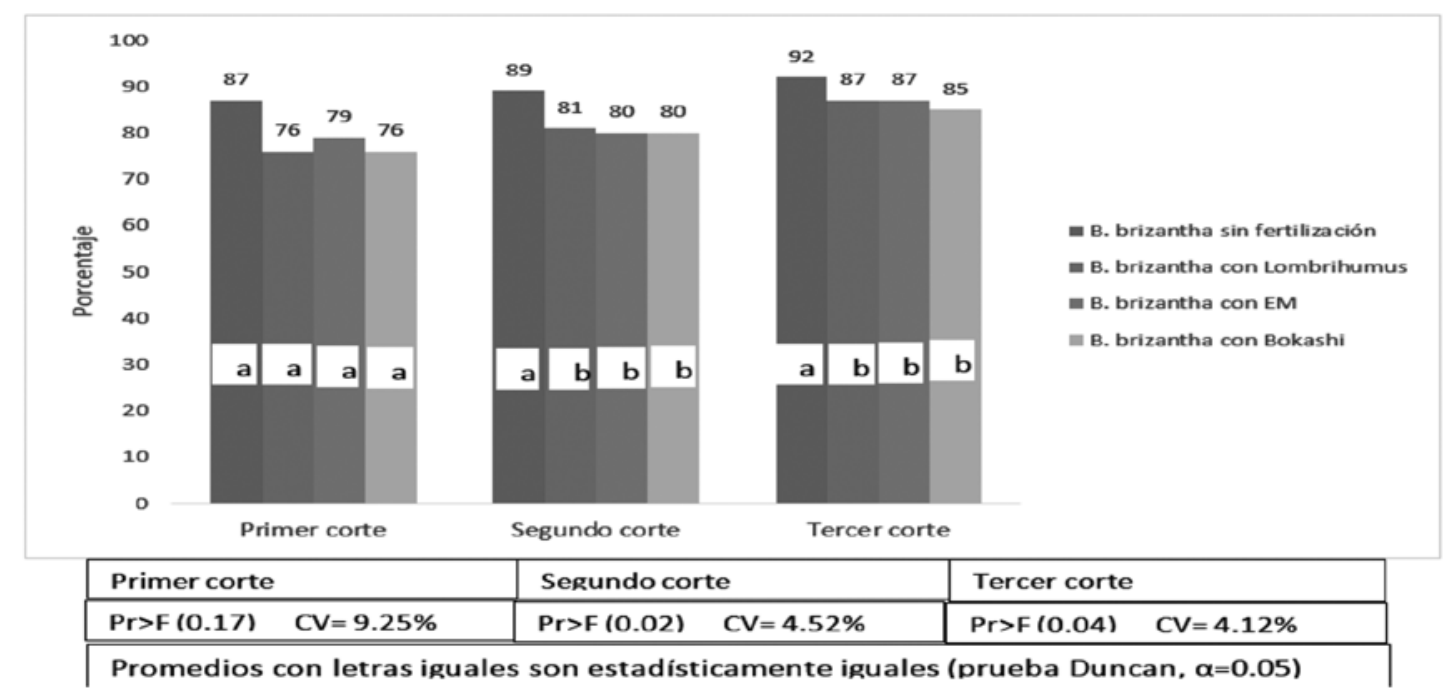

Figura 3: Cobertura (\%) de Brachiaria brizantha bajo diferentes alternativas de fertilización.

\section{Relación Hoja/Tallo}

No hubo efecto de los tipos de enmiendas ( $\mathrm{Pr}>0.05)$, es decir que la cantidad de hoja/tallo producida por los pastos no fue influenciada por el tratamiento aplicado (figura 4). Avellaneda (2008) encontró valores superiores al obtenido en este estudio cuando evaluó la relación hoja/tallo en Brachiaria brizantha. 


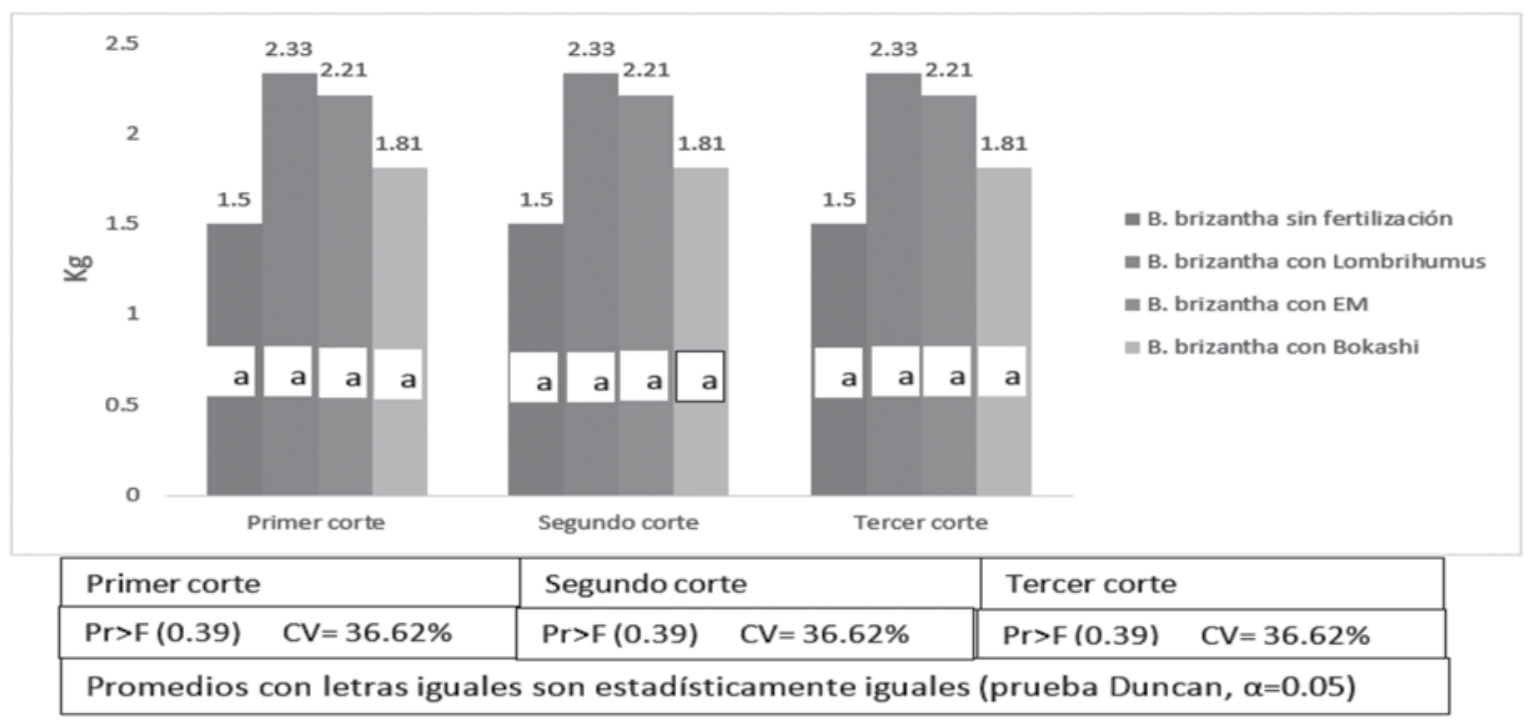

Figura 4: Relación hoja/tallo (Kg) de Brachiaria brizantha bajo diferentes alternativas de fertilización.

\section{Longitud de raíces primarias}

El ANDEVA evidencia un efecto significativo, el mayor tamaño de raíces primarias se obtuvo al aplicar Lombrihumus y EM (gráfico 5). Los resultados demuestran la efectividad que tienen las enmiendas orgánicas y el aporte que les brindan a las plantas para que estas puedan obtener mayor cantidad de nutrientes que posibilite la nutrición y vigor. Las raíces del pasto Brachiaria brizantha son profundas, lo que le permite sobrevivir bien durante períodos prolongados de sequía (Pérez, 2013).

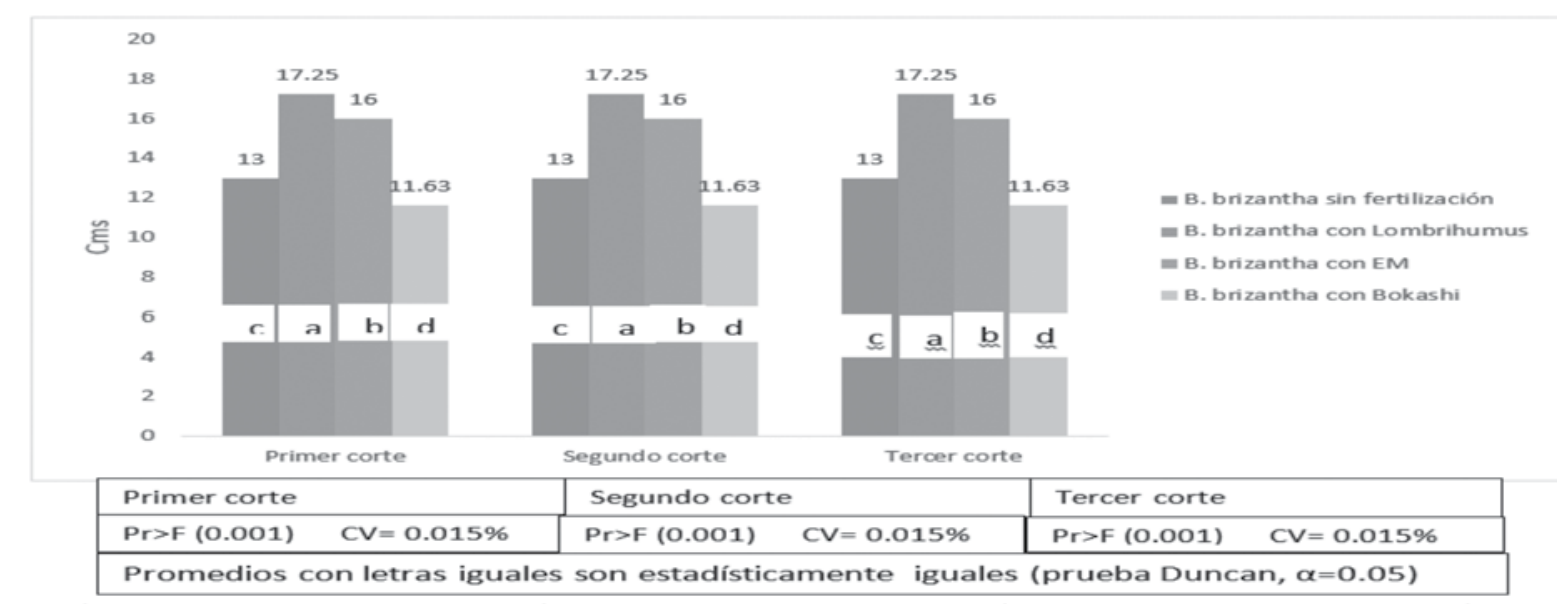

Figura 5: Longitud de raíces primarias (cm) de Brachiaria brizantha bajo diferentes alternativas de fertilización orgánica.

\section{Calidad del pasto Brachiaria brizantha}

Contenido de proteína bruta. El contenido de proteína en Brachiaria brizantha (figura 7) no está determinado por el tipo de abono que se aplique, al mostrar una sola categoría estadística para todos los tratamientos. 


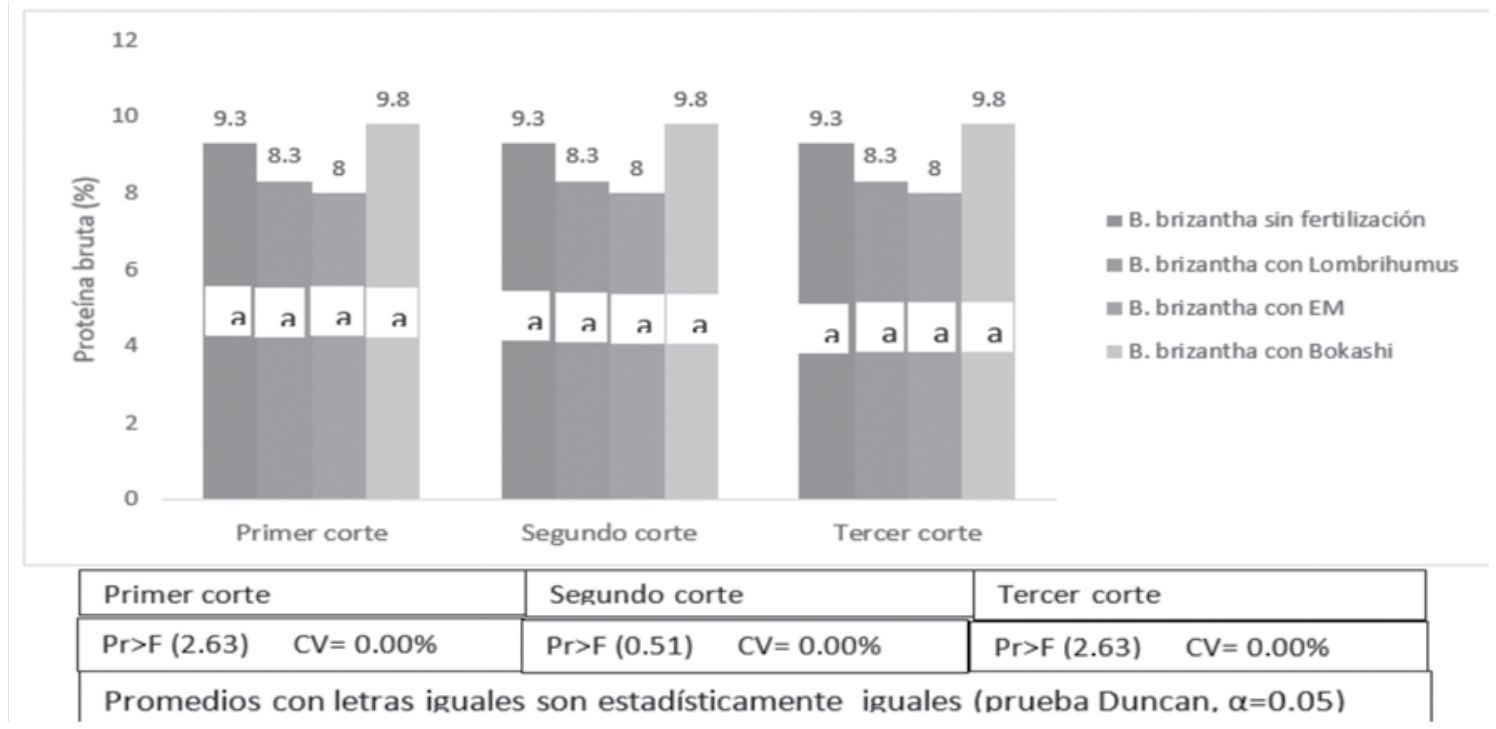

Figura 7: Contenido de proteína bruta (\%) de Brachiaria brizantha bajo diferentes alternativas de fertilización.

Contenido de cenizas. La figura 8, muestra una sola categoría estadística para todos los tratamientos. Las pasturas poseen una concentración de ceniza que oscila entre 7 a $13 \%$ en su contenido de materia seca (Trujillo, 2012). De acuerdo a Canchila (2009) la ceniza en Brachiaria presentó porcentajes entre 5,5 y 9,0\%.

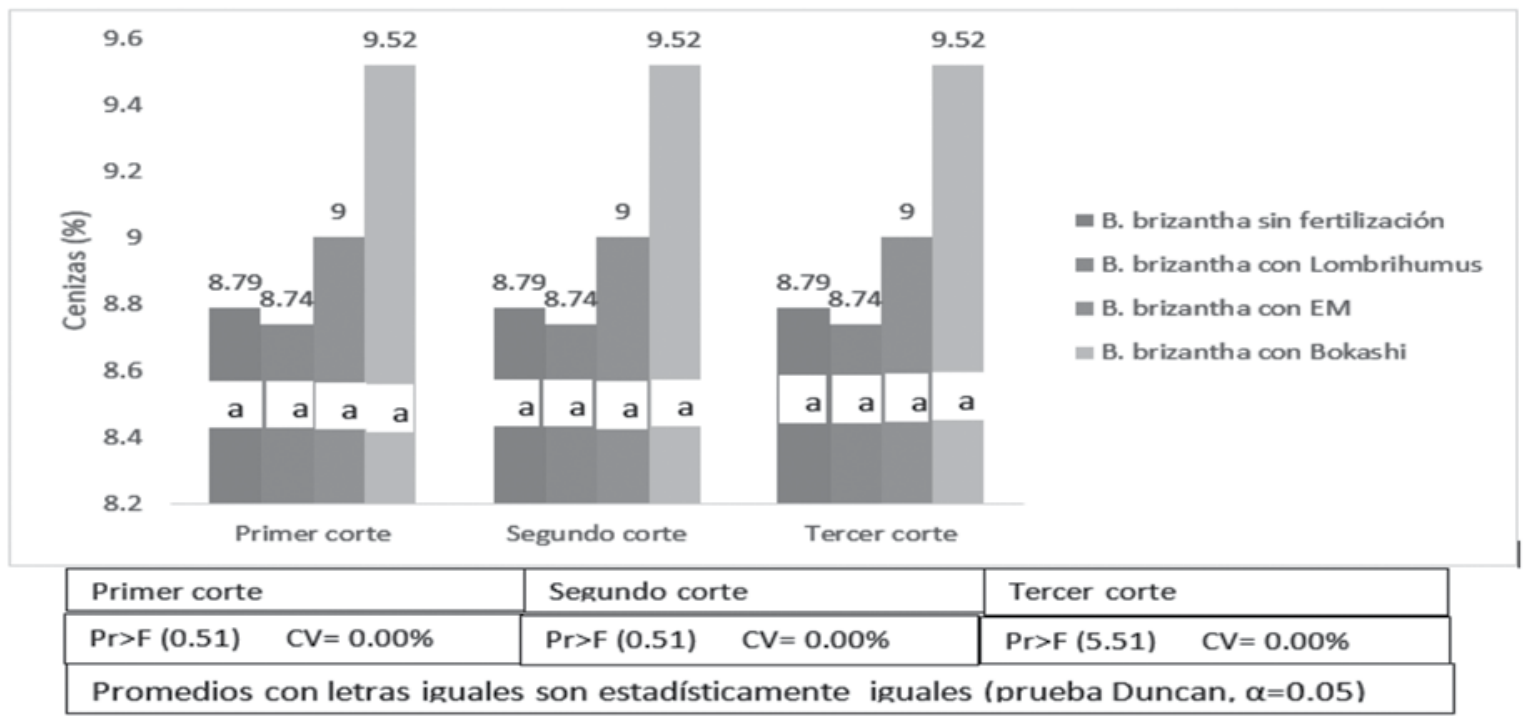

Figura 8: Contenido de cenizas (\%) de Brachiaria brizantha bajo diferentes alternativas de fertilización.

\section{Digestibilidad de la materia seca}

La separación de medias para la digestibilidad de la materia seca gráfico 9 indica que los mejores porcentajes se obtuvieron con el pasto manejado con Bokashi (62\%). El alto porcentaje de digestibilidad de materia seca del pasto Brachiaria brizantha está influenciado por la composición que posee, activa y aumenta la cantidad de microorganismos benéficos en el suelo con mayor contenido energético de la masa orgánica. De igual forma suministra hojas y tallos más tiernos lo que permite ser mejor aprovechado por los animales en su proceso de digestibilidad. En estudios realizados por Ramírez (2002) los porcentajes de digestibilidad de la materia seca en periodo lluvioso y poco lluvioso fueron entre $57 \%$ y $59 \%$ inferiores a este estudio. 
Por otro lado, Pérez (2013) reportados digestibilidad en el pasto Brachiaria brizantha de $61.8 \%$ con una frecuencia de corte de 35 días, muy similar a los datos obtenidos, la digestibilidad promedio de forraje producido por esta especie es de $66 \%$, con un rango que puede variar entre 56 y $75 \%$ dependiendo de la edad del rebrote.

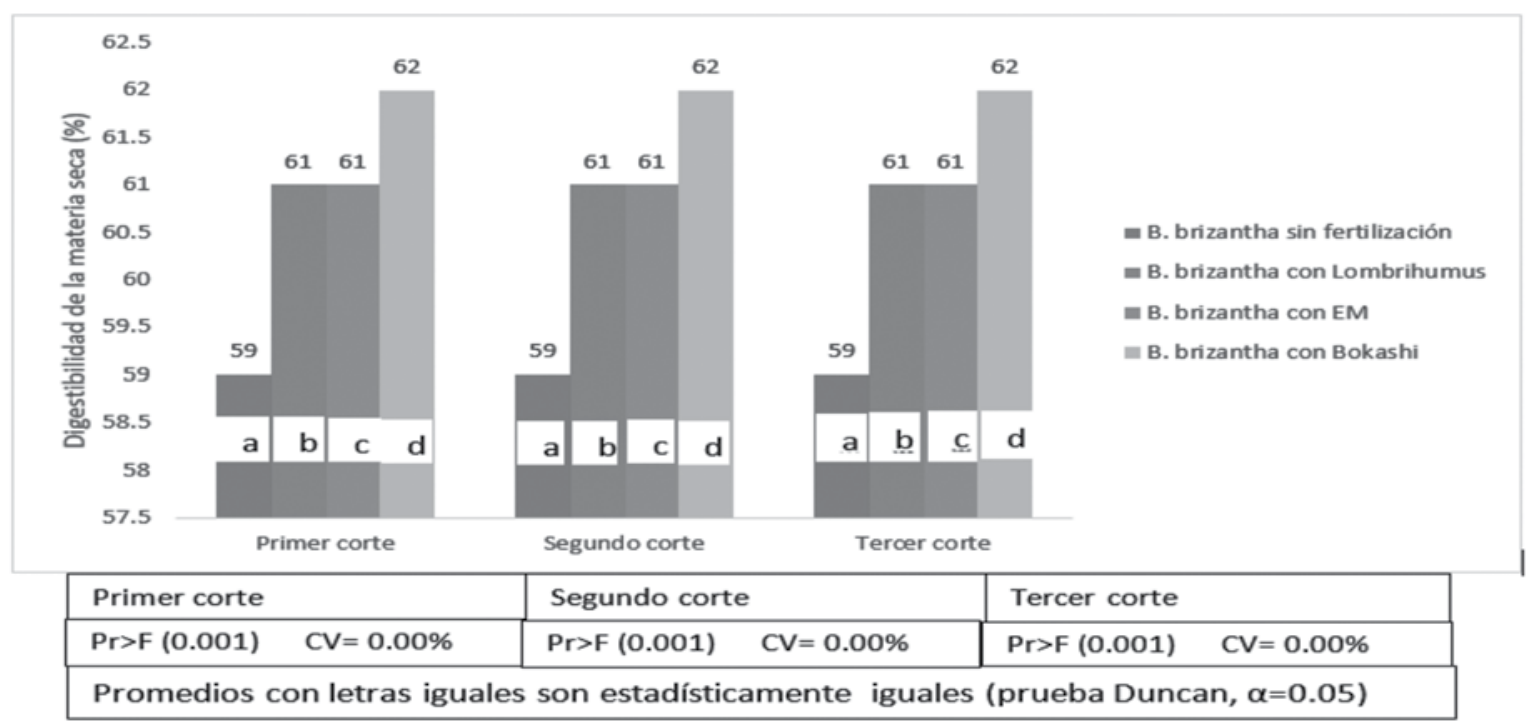

Figura 9: Digestibilidad de la materia seca (\%) de Brachiaria brizantha bajo diferentes alternativas de fertilización.

\section{Conclusiones}

Los mejores rendimientos de materia verde y materia seca se obtuvieron en el tercer corte al ser manejado con Lombrihumus y Bokashi. Los mayores rendimientos de proteína bruta, ceniza y digestibilidad de la materia seca se obtuvieron cuando al pasto Brachiaria brizantha se le aplicó abono orgánico Bokashi. Cuando el pasto Brachiaria brizantha es manejado con el abono orgánico Bokashi existe un mayor porcentaje de digestibilidad en las pasturas. Los abonos orgánicos que mayores efectos tuvieron en la evaluación de la pastura fueron el Bokashi y el Lombrihumus.

\section{Lista de referencia}

Aguilar, R. W. (1997). Efectos de diferencia de cortes sobre la producción de materia seca del pasto Brachiaria Brizantha. Managua, Nicaragua.

Avellaneda, C. J. (Marzo de 2008). Comportamiento agronómico y composición química de tres variedades de Brachiaria en diferentes edades de cosecha. Recuperado en: www.uteq.edu.ec/revistacyt/publico/ archivos/C2_articulo_5.pdf

BUILES, L. P. (16 de octubre de 2008). Artículos Zootécnicos . Recuperado el o3 de noviembre de 2013, de http://lilianazootecnia.blogspot.com/2008/10/subproductos-agropecuarios-y.html.

Calero, B.W. (2013). Diagnóstico socioeconómico y ambiental de la cordillera Yolaina. Estudio técnico. Nueva Guinea. 
Castro, T. L. (2010). Balance y potencial forrajero, periodo seco (Enero-Mayo, 2009), Hacienda las Mercedes. Managua.

Carrero, M. J. (26 de Marzo de 2012). Obtención y Evaluación del pasto Brechiaria Brizantha. Recuperado el 14 de Abril de 20124, de Obtención y Evaluación del pasto Brachiaria Brizantha: http://buenaproduccionanimal.wordpress.com/.

Campos, N. (2010). Evaluacion de cuatro difrentes abonos orgánicos (Humus, Bokashi, Vermicompos y Casting) en la producción pimaria forrajera de Brachiaria brizantha. Recuperado en: http://dspace.espoch.edu. ec/bitstream/123456789/1034/1/17To1029.pdf

Canchila. E.R, M. S. (2009). Evaluación de la composición bromatológica de 24 accesiones de Brachiaria spp. Recuperado en: http://scielo.sld.cu/scielo.php?script=sci_arttext\&pid=So864-03942009000400002

Delgadillo, L. G. (2009). Efecto del Kudzo (Pueraria Phasioloides) en el rendimiento y calidad de la leche, en monocultivo y asocio con Brachiaria brizantha cultivar marandu,. Nueva Guinea, RAAS.

FAO. (2012). Establecimiento y Manejo de Pasturas Mejoradas: la Briachiaria brizanta - See more at: http:// teca.fao.org/es/read/7544\#sthash.14yJymrs.dpuf. Recuperado el LUNES de NOVIEMBRE de 2013, de http://teca.fao.org/

Ganaderos, T. D. (2008). México Ganadero, S.A. de C.V. Obtenido de México Ganadero, S. A. de C.V.: http:// www.mexicoganadero.com/hatox.

Gutiérrez, D. (11 de junio de 2009). Abonos orgánicos. Recuperado el 14 de Mayo de 2014, de http://deyaniragutierrezdiaz.blogspot.com

IPADE-PRODESOC. (2009). Abono Orgánico. El Castillo, Río San Juan. 18 p.

Miranda, Z. H. (Abril de 2009). Adaptación y productividad de seis gramíneas Forrajeras en Puerto Díaz, Chontales, Nicaragua, 2007. Managua.

Pérez, M. G. (2013). Brachiaria Brizantha. Recuperado en septiembre de 2013, de http://www.nufarm.com/

Prado, M. T. (2004). Efecto de la fertilización química y orgánica en el pasto (brachiaria brizantha) en el municipio de Nueva Guinea, nicaragua. Nueva Guinea.

Ramírez, C. A. (2002). Ganadería de Leche, Enfoque Empresarial. San José Costa Rica: Primera Edición EUNED San Jose Costa Rica.

Roig, C. c. (2010). Evaluación de cuatro diferentes de abonos orgánicos (Humus, Bokashi, Vermicompos y Casting), en la producción primaria forrajera de la Brechiaria brizantha. Recuperado el Abril de 2015.

Trujillo, A. I. (2012). VALOR NUTRITIVO DE LAS PASTURAS. Recuperado el Lunes de Junio de 2015, de http://prodanimal.fagro.edu.uy 